\title{
DESENVOLVIMENTO DE REVESTIMENTOS CONTENDO ADIÇÕES DE CINZAS DA COMBUSTÃO DA CASCA DO ARROZ
}

\author{
L. M. M. MACHADO ${ }^{1}$, M. C. BRANDÃO ${ }^{1}$, L. M. RODRIGUES ${ }^{1}$ e S. N. da SILVA ${ }^{2}$ \\ ${ }^{1}$ Universidade Federal do Pampa, Campus Bagé, Engenharia Química \\ ${ }^{2}$ Universidade Federal do Pampa, Campus Bagé, Engenharia de Energias Renováveis e \\ Ambiente \\ E-mail para contato: sabrinasilva@unipampa.edu.br
}

\begin{abstract}
RESUMO - Neste trabalho avaliamos a possibilidade de aproveitamento das cinzas da casca de arroz (CCA) como carga em resina alquídica, aplicada como revestimento anticorrosão, com a finalidade de melhorar a propriedade de barreira conferida pelo revestimento. A característica de barreira pode ser atribuída ao fato de as cargas aumentarem o caminho da difusão do $\mathrm{O}_{2}$ e da $\mathrm{H}_{2} \mathrm{O}$ até a interface polímero/metal. Além disso, alguns dos óxidos, constituintes químicos das cinzas de casca de arroz, possuem propriedades inibidoras das reações de corrosão. Analisamos a dispersão do tamanho e a morfologia das partículas por curvas de distribuição granulométrica por espalhamento de luz e por microscopia ótica (MO). As imagens obtidas foram analisadas no software Image J. A caracterização dos revestimentos foi realizada por difratometria de raios-X (DRX) e Espectroscopia de Infravermelho por Transformada de Fourier (FTIR). Desenvolvemos revestimentos com diferentes concentrações de cinzas $(0,5$ e $10 \%$ em massa) e aplicamos sobre placas de aço inoxidável 304. O desempenho da resina com e sem as cargas foi avaliado pela exposição em câmara climática com umidade relativa (UR) e temperatura controladas.
\end{abstract}

\section{INTRODUÇÃO}

A cinza da casca de arroz (CCA) possui, como maior componente químico, o dióxido de silício $\left(\mathrm{SiO}_{2}\right)$, variando entre 74 a $97 \%$, independendo do processo de queima (Tashima et al., 2004). O elevado teor de sílica torna a CCA valorizada, mas este resíduo só terá valor econômico se tiver alta qualidade, caracterizada pela elevada superfície específica, tamanho e pureza de partícula, podendo ser usado em diversas aplicações. A queima da casca do arroz também tem sido empregada para a geração de energia elétrica, devido ao elevado poder calorífico deste material. Esta é uma alternativa praticável do ponto de vista tecnológico, viável do ponto de vista econômico e ética do ponto de vista ecológico, uma vez que existe tecnologia para a conversão (Foletto et al., 2005).

Entre os vários re-usos para cinzas, pode-se citar: produção de cimento pozolânico, obtenção de agregados leves para concreto, estabilização de solos, fabricação de concreto celular, produção de materiais construtivos a base de cinza-cal. Cerca de $30 \%$ das cinzas atualmente produzidas é aproveitada na indústria cimenteira, o restante é descartado (Casagrande et al., 2008). Deste modo, é importante que novas investigações sejam 
desenvolvidas no sentido de procurar novas aplicações para as cinzas, reduzindo, assim, os impactos ambientais.

As técnicas industriais mais empregadas para a captura desses resíduos sólidos são os precipitadores eletrostáticos, os filtros de manga, os lavadores úmidos e os coletores mecânicos. Para descarte das cinzas existem, basicamente, dois métodos: as lagoas de sedimentação e os aterros sanitários.

O aproveitamento da CCA tem importância ambiental, pois quando descartada de forma inadequada, provoca poluição por apresentar certa quantidade de carbono residual. A cinza é considerada altamente prejudicial para a saúde humana, devido ao elevado teor de sílica que pode ocasionar uma doença pulmonar conhecida como silicose. A geração de resíduos na agroindústria tem causado grande preocupação, visto que seu descarte vem desencadeando diversos problemas ambientais, como a poluição do solo, de mananciais e até mesmo do ar (Della et al., 2005).

Considerando esses fatos, o presente trabalho propõe uma forma inovadora e ambientalmente correta de uso da cinza da casca de arroz como carga anticorrosão para composição de tintas.

Com o intuito de minimizar os processos corrosivos, diversos métodos de proteção contra a corrosão são utilizados com o objetivo de evitar, prevenir ou impedir a formação de produtos de corrosão. O uso de tintas e revestimentos protetores sobre superfícies metálicas é o método mais usual, formando uma barreira entre o metal e o meio corrosivo e, consequentemente, impedindo ou minimizando o processo de corrosão atmosférica (Almeida e Panossian, 1999).

Revestimentos que protegem por mecanismo de barreira possuem sólidos insolúveis de formato lamelar que retardam ou impedem que reagentes da reação catódica alcancem a superfície metálica, bloqueando a passagem, por exemplo, de oxigênio e água. Revestimentos que agem por mecanismo de barreira são vantajosos, devido ao baixo custo, à facilidade na fabricação e aplicação, e à vasta gama de produtos disponíveis (Sangaj e Malshe, 2004).

\section{MATERIAIS E MÉTODOS}

Para os experimentos utilizou-se resina alquídica de cadeia longa para revestimento decorativo, fornecida pela Empresa Renner. Foram adicionadas cinzas de casca de arroz (CCA) nas proporções de 0,5 e $10 \%$ em massa. Os revestimentos foram aplicados sobre chapas de aço inoxidável AISI 304. E a cinza utilizada neste estudo foi coletada em indústria de beneficiamento de arroz, na cidade de Dom Pedrito - RS, sendo coletada logo após à queima. Essa cinza foi moída e seca em estufa a $60^{\circ} \mathrm{C}$ até massa constante, após foi mantida sob vácuo até a aplicação.

$\mathrm{Na}$ caracterização dos concentrados foram utilizadas as técnicas de análise química de Difratometria de Raios-X (DRX), Espectroscopia $\mu$-Raman e de Infravermelho por Transformada de Fourier (FTIR). A morfologia foi investigada por análise de imagens obtidas por microscópio ótico (MO). Também foi usada a técnica de Dispersão de tamanho de partículas. 
A Figura 1 mostra um fluxograma do procedimento de preparo das tintas. Para comparação de desempenho, durante os ensaios em atmosfera controlada, foi utilizada uma amostra não contendo cinzas.

Figura 1 - Fluxograma do procedimento de preparo dos concentrados.

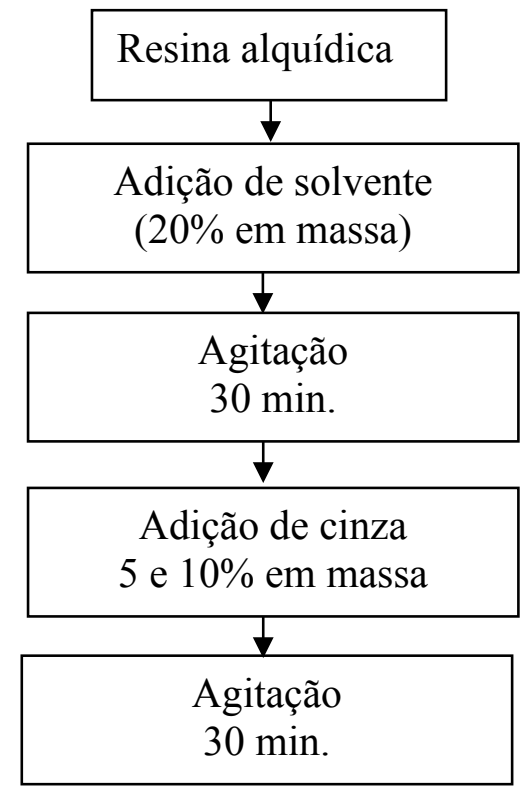

O revestimento foi aplicado sobre placas de aço AISI 304 laminado a frio e com espessura de 1 centímetro fabricado pela Maller Inox. A composição química, expressa em \% em massa, fornecida pelo fabricante, pode ser verificada na Tabela 1. As dimensões das placas foram $1,5 \times 3 \mathrm{~cm}$.

Tabela 1 - Composição química (\% em massa) do aço inoxidável AISI 304.

\begin{tabular}{|c|c|c|c|c|c|c|c|c|}
\hline \multicolumn{7}{|c|}{ Composição Química (\% em massa) } \\
\hline C máx. & Mn máx. & P máx. & S máx. & Si máx. & $\mathrm{Ni}$ & $\mathrm{Cr}$ & $\mathrm{N}$ máx. & Fe \\
\hline 0,08 & 2,00 & 0,045 & 0,030 & 0,75 & $8-10$ & $18-20$ & 0,10 & Balanço \\
\hline
\end{tabular}

As superfícies metálicas foram lixadas com lixa \#220, a fim de produzir uma rugosidade satisfatória para promover boa adesão ao substrato. Após, as amostras foram limpas com água destilada e etanol, secas em estufa a $60^{\circ} \mathrm{C}$ durante 30 min e mantidas sob vácuo até a aplicação dos revestimentos.

A técnica de aplicação da tinta visou garantir a maior espessura possível de filme úmido sobre a placa sem haver escorrimento da mesma. O recobrimento foi realizado por imersão da amostra metálica, conforme mostra a Figura 2. O procedimento foi repetido quatro vezes. 
Figura 2 - Método de aplicação da pintura.

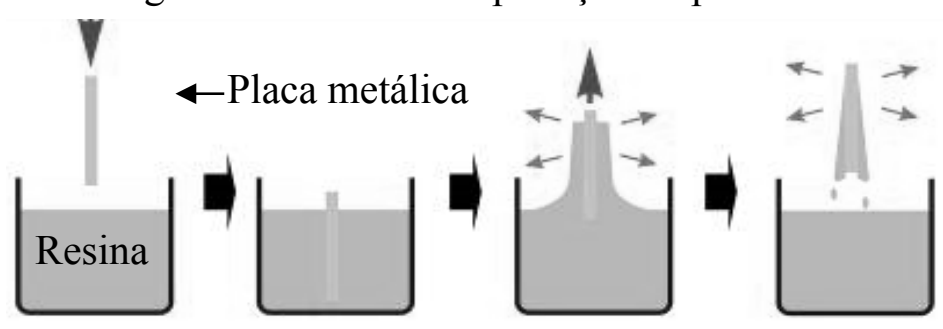

As amostras utilizadas nos ensaios de atmosfera controlada (temperatura e umidade relativa) foram colocadas em duplicata na câmara climática, totalizando oito amostras. $\mathrm{O}$ período total de exposição foi de 164 horas. A cada $24 \mathrm{~h}$ adquiriu-se uma imagem da amostra.

As placas revestidas sofreram uma incisão em forma de "X", Figura 3, com o objetivo de verificar a progressão da corrosão a partir de uma falha no revestimento. Os ensaios foram avaliados pelas normas ASTM D714 para quantificação de tamanho e frequência de bolhas, bem como a norma ASTM D610 para avaliação de enferrujamento.

Figura 3 - Incisão na placa metálica para avaliação do grau de enferrujamento.

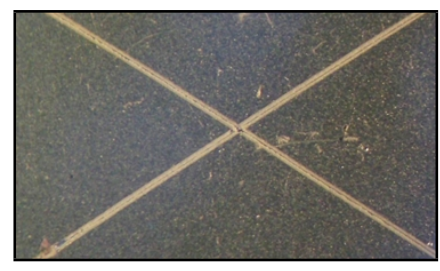

\section{RESULTADOS E DISCUSSÃO}

A dispersão do tamanho das partículas de CCA, analisada em granulômetro a laser é mostrada na Figura 4. Com base nesses resultados pode-se observar que o diâmetro médio das partículas é de 52,29 micrômetros.

Figura 4 - Distribuição granulométrica da CCA.

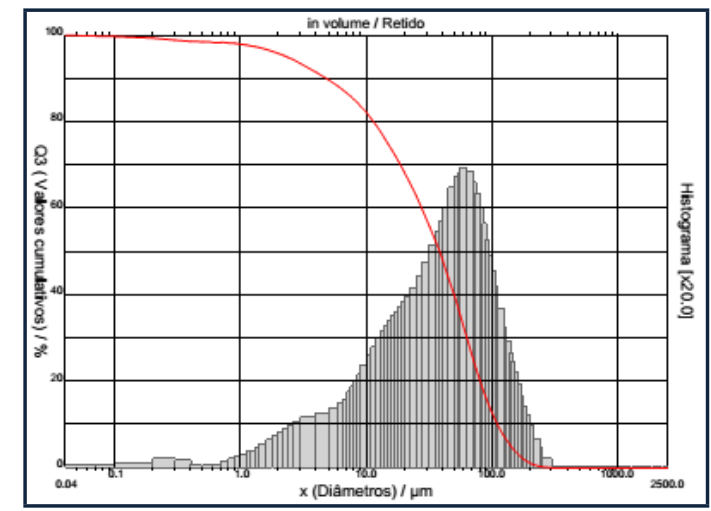

As fases encontradas na CCA, conforme resultado da análise de DRX, podem ser visualizados na Figura 5 e estão sumarizados na Tabela 2. 


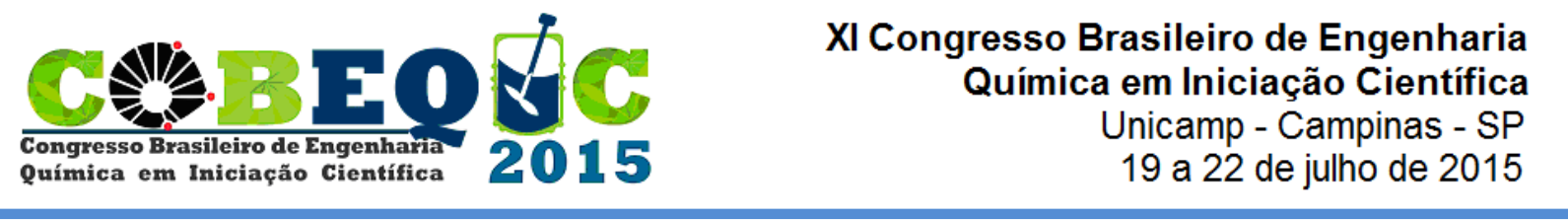

Figura 5 - Difratograma do filme puro e composto.

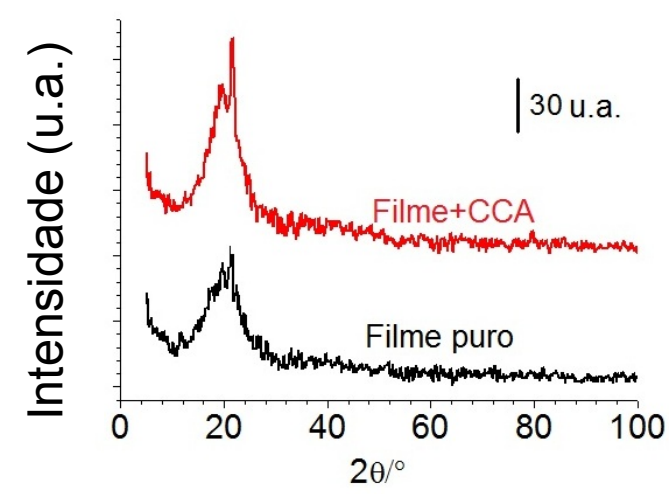

Tabela 2 - Fases encontradas nos concentrados.

\begin{tabular}{|c|c|c|}
\hline Fase & Fórmula & $2 \theta /{ }^{\circ}$ \\
\hline Quartzo & $\mathrm{SiO}_{2}$ & 21 e 27 \\
\hline Caulinita & $\mathrm{Al}_{2} \mathrm{Si}_{2} \mathrm{O}_{7} .2 \mathrm{H}_{2} \mathrm{O}$ & 20,28 \\
\hline Calcita & $\mathrm{CaCO}_{3}$ & $26,34,40$ \\
\hline Rutilo & $\mathrm{TiO}_{2}$ & 25,27 \\
\hline Hematita & $\mathrm{Fe}_{2} \mathrm{O}_{3}$ & 30 \\
\hline Siderita & $\mathrm{FeCO}_{3}$ & 33 \\
\hline Pirita & $\mathrm{FeS}_{2}$ & 40 \\
\hline
\end{tabular}

Por FTIR foram encontradas bandas características das vibrações internas no tetraedro $\mathrm{TO}_{4}(\mathrm{~T}=\mathrm{Al}, \mathrm{Si})$. Estes tetraedros são unidades básicas de construção de alumina $(1,2)$ e sílica (3), conforme pode ser visualizado na Figura 6.

Figura 6 - Espectros de FTIR do filme puro e composto.

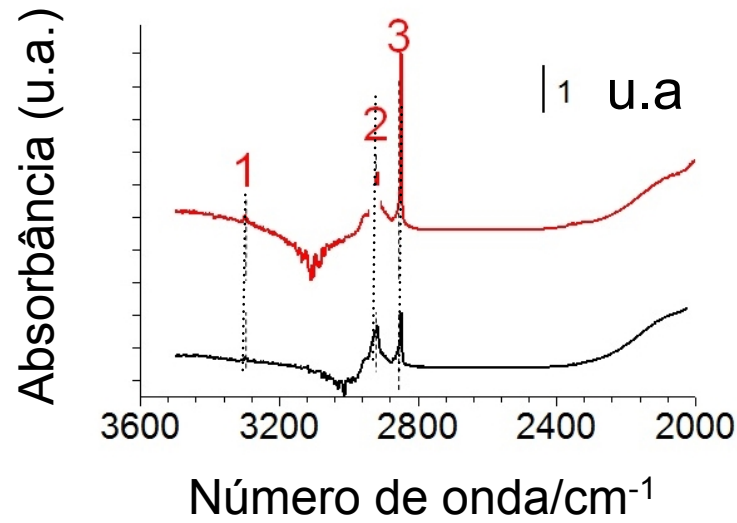

Nos ensaios em atmosfera controlada, observou-se, após 164 horas de exposição, que o revestimento sem carga, teve o mais baixo desempenho nos ensaios de corrosão. Após 20 horas o revestimento já apresentava bolhas, indicando que houve infiltração de água no filme, possivelmente devido à delaminação deste, conforme mostrado na Figura 7 (a). Com a adição de $10 \%$ de CCA a amostra manteve sua integridade, mesmo após 164 horas de exposição, Figura 7 (b). 
Figura 7 - Amostras expostas ao ensaio de atmosfera controlada (a) sem carga após 20 horas e (b) com 10\% de CCA após 164 horas.
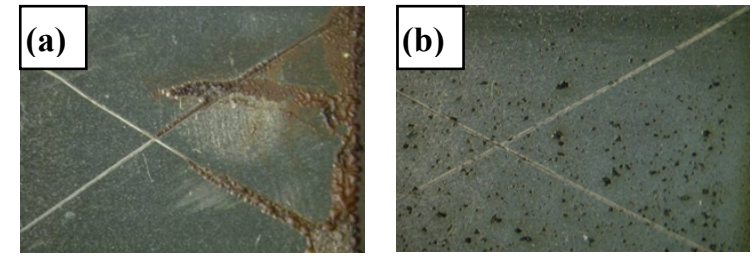

\section{CONCLUSÕES}

Quanto aos objetivos propostos, pode-se concluir que:

- Foi proposta uma alternativa inovadora e ambientalmente correta de uso da cinza da casca do arroz como carga anticorrosão para composição de tintas.

- A CCA promove efeito inibidor às tintas aumentando a resistência à corrosão do aço AISI 304, conforme verificado nos ensaios de atmosfera controlada.

- O efeito inibidor deve-se principalmente à característica de barreira atribuída ao fato das cargas aumentarem o caminho da difusão do $\mathrm{O}_{2}$ e da $\mathrm{H}_{2} \mathrm{O}$ até a interface polímero/metal. Além disso, óxidos, principalmente de $\mathrm{Si}$ e $\mathrm{Al}$, constituintes químicos das cinzas, possuem propriedades inibidoras das reações de corrosão.

\section{REFERENCIAS}

ALMEIDA, N.; PANOSSIAN, Z. Corrosão Atmosférica: 17 anos. São Paulo: IPT, 1999.

CASAGRANDE, M. C.; SARTOR, M. N.; GOMES, V.; DELlA, V. P.; HOTZA, D; OLIVEIRA, A. P. N. Reaproveitamento de Resíduos Sólidos Industriais. Cerâmica Industrial, $\mathrm{n}^{\circ}$. 13, Janeiro/Abril, p. 34-42, 2008.

DELLA, V. P.; KÜHN, I.; HOTZA, D. Reciclagem de resíduos agro-industriais: Cinza de casca de arroz como fonte alternativa de sílica. Cerâmica Industrial, v. 10, p. 22-25, 2005.

FOLLETO, E. L.; HOFFMAN, R.; HOFFMAN, R. S.; PORTUGAL Jr., V. L.; Jahn, S. L. Aplicabilidade das cinzas da casca de arroz. Química Nova, v. 28, p. 1055-1060, 2005.

GENTIL, V.. Corrosão. 5 ${ }^{\text {a }}$ Edição, Rio de Janeiro: LTC, 2008.

SANGAJ, N. S.; MALSHE, V. C. Permeability of Polymers in Protective Organic Coatings. Progress in Organic Coatings, v. 50, p. 28-39, 2004.

TASHIMA, M. M.; SILVA, C. A. R. L.; AKASAKI, J. L. Concreto com adição de cinza de casca de arroz (CCA) obtida através de um processo de combustão não controlada. In: Jornadas Sud-Americanas de Ingeniería Estructural, 31, 2004, Mendonza, Argentina. 